\title{
Implication of Mode of Consumption of Allium cepa L. (Onion) on Lipoglycemic and Anthropometric Impacts in Diabetic Rats: A Function of Choice
}

\author{
Magnus Michael Chukwudike Anyakudo* and Peace Olubukola Akinyemi \\ Endocrinology, Metabolism and Clinical Nutrition Research Unit of Department of Physiology, University of Medical Sciences, Nigeria
}

Submission: July 19, 2021; Published: August 02, 2021

*Corresponding author: Magnus Michael Chukwudike Anyakudo, Endocrinology, Metabolism and Clinical Nutrition Research Unit of Department of Physiology, Faculty of Basic Medical Sciences, University of Medical Sciences, P.M.B 536, Ondo City, Ondo State, Nigeria 4840

\begin{abstract}
Background: Use of Allium cepa L. (Onion) as spice in traditional cooking, concoctions and preparations has long been established since ancient time. However, the implication of its mode of consumption on health benefits is inadequately considered or explored.
\end{abstract}

Objectives: This experimentally-controlled designed nutritional study aimed to determine and compare the effects of consumption of Allium cepa in its raw form and in mixed meal on body weight, glycemic tolerance/control and, lipid profile in diabetic rats.

Materials and Methods: Twenty one adult (170-200g) male Wistar rats were randomly categorized into three experimental groups (n=7, each): Diabetic Control (DC), Diabetic Onion Extract-Treated (DOE), and Diabetic Onion-supplemented Diet-Fed (DSO). Diabetes was inducted with $150 \mathrm{mg} / \mathrm{dL}$, alloxan monohydrate solution intraperitoneally. Animals were fed according to the experimental design with water ad libitum for six weeks. Body weights and Fasting blood sugar (FBS) concentrations were measured twice weekly. LP and OGTT were conducted. Microsoft Excel and statistical SPSS program version 22 were used for data analysis. Results are expressed as mean \pm SEM. Comparison between groups were made using Students't-test and one way ANOVA.

Results: Consumption of onion in its raw (aqueous extract) form caused more reduction in blood glucose concentration (DOE - 38.14\% versus DSO - 11.2\%; $\mathrm{P}=0.02$ ) and body weight gain (DOE - 7.71\% versus DSO - 16.32\%; $\mathrm{P}=0.01$ ), with improved lipid profile than when ingested in mixed meal (supplemented diet). Glycemic response curves peaked at 60 minutes of glucose challenge in DSO and DOE groups.

Conclusion: Mode of consumption of Allium cepa, influenced its therapeutic anthropometric and lipoglycemic effects in diabetic rats.

Keywords: Diabetic rats; Glycemic tolerance; Lipid profile; Mode of consumption; Onion; Weight gain

Abbreviations: FBS: Fasting Blood Sugar; OGTT: Oral Glucose Tolerance Test; ANOVA: Analysis of Variance; SPSS: Social Package for Social Science; SEM: Standard Error of Mean

\section{Introduction}

The use of onion as a nutraceutical has become of increasing interest in the recent years largely due to an increase in the availability of evidence-based findings demonstrating its numerous health benefits in treating diverse disease conditions. Allium cepa commonly known as "onion" is one of the most widely used vegetables in the world cuisine and is generally consumed in foods. Many health benefits of onion have been attributed to its several constituent organic and inorganic compounds such as flavonoids and organosulfur compounds [1-4]. Onions vary in size, shape, favour and colour (most common types being red, yellow, and white). Various research studies on onion revealed that onion possesses antioxidant [5], anti-inflammatory [6], hypoglycaemic [7], antibacterial [8], immune and bone boosting properties [9]. Onion is consumed in different forms which vary from one culture to another. Most often, onion is consumed as spice in traditional cooking, concoctions and preparations. While some people take onion in its raw form in some cuisine, some preferred it boiled or fried in prepared diets. Most studies investigating the potentiality of onion (Allium cepa) in human subjects and animal models administered the onion as a direct oral aqueous extract or gel while very few tried incorporating it into the test diet in 
a dry powder form. Whether the mode of consumption of this herbaceous plant has effect or not on its health benefits was the central focus of this study which investigated and compared the impact of mode of consumption of onion in its raw form and in mixed meal on body weight gain, glycemic tolerance/control and, lipid profile in diabetic rats with the rationale to provide basis for dietary selection, advice and recommendations for optimal therapeutic effects.

\section{Materials and Methods}

\section{Preparation of aqueous extract of Allium cepa}

The onion bulb was washed and properly cleaned with distilled water. The outer covering of the bulb was peeled off and the fleshy part of the onion was washed with distilled water and weighed. $226 \mathrm{~g}$ of onion was homogenized with $50 \mathrm{ml}$ of distilled water to a fine texture form with an electric blender. The mixture obtained was filtered using a fine muslin cloth to produce the extract. The extract was weighed and stored in a clean container, kept in refrigerator at $4^{\circ} \mathrm{C}$. Fresh portions of the extract were prepared weekly.

\section{Toxicity test}

An acute toxicity test using modified stair-case method [1012] was conducted for the extract. The rats were provided orally with increasing fixed doses of $1,2,3$, and $4 \mathrm{~g}$ of onion extract per kg body weight while the toxicity was assessed by mortality and behavioural changes in the rats.

\section{Test feed and composition}

The composition of the control and onion-supplemented diets in this study was prepared based upon the standard diet formulas used to assess weight gain in rodents during commercial feeding studies (Table 1).

Table 1: Percentage composition of experimental (control and test) diets.

\begin{tabular}{|c|c|c|c|}
\hline Nutrient Components & Ingredients Used & $\begin{array}{c}\text { Normal Diet (Control) (\% per 100g } \\
\text { of feed) }\end{array}$ & $\begin{array}{c}\text { Onion-Supplemented (Test) Diet } \\
\text { (\% per 100g of feed) }\end{array}$ \\
\hline Carbohydrates & Maize & $40 \%$ & $40 \%$ \\
\hline & Wheat offal & $15 \%$ & $15 \%$ \\
\hline Fat and Oil & Palm kernel cake & $20 \%$ & $20 \%$ \\
\hline & Groundnut cake & $10 \%$ & $10 \%$ \\
\hline Protein & Soya bean meal & $10.50 \%$ & $1.00 \%$ \\
\hline & Oyster shell & $1.00 \%$ & $3.00 \%$ \\
\hline Vitamins & Bone meal & $3.00 \%$ & $0.15 \%$ \\
\hline Mineral Salt & Growth premix & $0.25 \%$ & $0.25 \%$ \\
\hline ADDITIVES & Salt & $0.25 \%$ & $0.10 \%$ \\
\hline & Onion & $-100 \%$ & $100 \%$ \\
\hline
\end{tabular}

\section{Experimental animals and diets}

Twenty-one male Wistar rats (Rattus norvegicus) weighing about 170-200g used for this study were obtained from the disease-free stock of Olu farm, Ibadan, Oyo state, Nigeria. The animals were kept in polypropylene cages with stainless wire mesh top in well ventilated animal house maintained at normal and standard laboratory conditions of temperature and relative humidity for two weeks to allow them acclimatize to the environment. During these two weeks, they were fed with commercially available standard rat feed (Ladokun feeds Nig. Ltd.) and water ad libitum. Replaceable numbered blotters papers were placed under each cage to catch the spilled diet that was measured to make up for the daily serving ration. The rats were weighed twice weekly to ensure that no rat outside the range of $170-200 \mathrm{~g}$ was used at entry point.

\section{Induction of diabetes}

After two weeks of acclimatization, all rats were fasted overnight (15 hours) for diabetes induction achieved with freshly prepared alloxan monohydrate (Kermel chemicals, CHINA) dissolved in sterile normal saline at a dose of $150 \mathrm{mg} / \mathrm{kg}$ body weight. Diabetes was confirmed four days later using a glucometer (Fine Test Blood Glucose Monitoring System, OSANG Healthcare Co., Ltd., Korea). Rats with fasting blood sugar (FBS) level above $150 \mathrm{mg} / \mathrm{dL}$ were selected and grouped into three experimental groups according to the experimental design.

\section{Experimental design}

The animals were grouped into three groups $(n=7$, each group) after induction as follows:

a) Group DC: Diabetic rats fed with normal diet (Control)

b) Group DOE: Diabetic rats fed with normal diet and treated with onion aqueous extract diet

c) Group DSO: Diabetic rats fed with onion-supplemented

To determine the effects of onion on body weight, lipid profile and glycemic status, rats in groups DC and DOE were fed with 
standard rat feed throughout the period of the study while DSO rats were fed with onion-supplemented diet only. In addition, DOE rats were treated with onion aqueous extract $(4 \mathrm{~g} / \mathrm{kg}$ body weight/day) administered orally by orogastric cannular. The rats were monitored twice daily for food and water intake while body weight and FBS were assessed bi-weekly and recorded. The investigations using experimental animals were conducted in accordance with the internationally accepted principles for laboratory animal use and care [13] as found in the United States Guidelines (United States National Institutes for Health Publication No. 85-23, revised in 2017).

\section{Blood collection and biological assay}

Blood samples were collected from tail veins (for OGTT) and by cardiac puncture (for lipid profile). Blood glucose concentrations were measured using glucometer while blood samples obtained by cardiac puncture were stored in $\mathrm{K}_{3}$ EDTA bottles for lipid profile analysis.

\section{Glycemic tolerance test}

After 15-hour overnight fast with free access to water, all animals in the groups were treated with oral D glucose load of $2 \mathrm{~g} / \mathrm{kg}$ body weight dissolved in distilled water and administered by flexible metal orogastric cannula. Thereafter, blood samples were withdrawn from the tail vein of each rat for blood glucose concentrations assessment taken at 30 minutes intervals for $2 \mathrm{hrs}$.

\section{Lipid profile test}

The lipid profile was conducted at the onset and on the $6^{\text {th }}$ week of study for comparison. Blood samples from the Posterior Vena Cava vein were collected and transferred into the k3 EDTA
(Ethylene Diamine Tetraacetic Acid) sample bottles. Samples were centrifuged at 3000 revolutions to obtain the plasma fractions which was kept in a refrigerator (at $-70^{\circ} \mathrm{C}$ ) until used and the sera obtained were used for the biochemical assay of the lipid profile. Plasma concentration of total cholesterol (TC), high density lipoprotein (HDL) and Triacylglycerol (TAG) were measured by the enzymatic colorimetric method after centrifugation using a dry-chemical automatic analyzer AU-5200 OLYMPUS (Randox Laboratories, San Francisco, USA). LDL level was determined by the Friedewald formula [14] as follows:

$$
\begin{gathered}
\text { VLDL }(\mathrm{mg} / \mathrm{dL})=\mathrm{TAG} / 5 \\
\mathrm{LDL}(\mathrm{mg} / \mathrm{dL})=\mathrm{TC}-\mathrm{VLDL}-\mathrm{HDL}
\end{gathered}
$$

\section{Statistical analysis}

Microsoft Excel and statistical SPSS program version 22 were used for data analysis. Results are expressed as group mean \pm SEM. Comparison between groups were made using Students'ttest and one way ANOVA. Significance level was set to $\mathrm{P}<0.05$.

\section{Results}

\section{Effect of Allium cepa on body weight and weight gain}

The initial and final mean body weights for each animal category are shown in Table 2. Onion consumption caused a significant $(P<0.05)$ decrease in mean weight gain in DSO $(16.32 \%)$ and DOE $(7.71 \%)$ rats compared with the diabetic control rats (28.74\%). Difference in weight gain between DOE and DSO rats was significant $(P=0.01)$. The weight-lowering effect of onion in experimental diabetic rats was more pronounced in group treated with raw onion.

Table 2: Effect of onion on body weight and weight gain ( $n=5 /$ group).

\begin{tabular}{|c|c|c|c|}
\hline \multirow{2}{*}{ Parameters } & \multicolumn{3}{|c|}{ Experimental Diabetic Animal Groups } \\
\cline { 2 - 4 } & Control DC & Onion-Supplemented Diet-fed DSO & Onion Extract Treated DOE \\
\hline Final Mean Weight (g) & $222.2 \pm 17.8$ & $201 \pm 10.7$ & $187.2 \pm 11.7$ \\
\hline Initial Mean Weight (g) & $172.6 \pm 7.2$ & $172.8 \pm 5.9$ & $173.8 \pm 7.6$ \\
\hline \% Mean Weight Gain & $28.74 \%$ & $16.32 \%$ & $7.71 \%$ \\
\hline
\end{tabular}

Values are expressed in mean \pm SEM, Significant $(P<0.05)$

\section{Effect of Allium cepa on glycemic status}

The hypoglycemic effect of onion on venous mean FBS concentrations $(\mathrm{mg} / \mathrm{dL})$ in diabetic rats is shown in Table 3. A significant $(P<0.05)$ reduction in mean FBS concentrations was observed in both DOE and DSO rats compared with the control. However, the difference in their FBS values was comparably significant $(P=0.02)$. This observation revealed that raw (extract) onion has more antihyperglycemic effect than onion consumed in mixed meal.

\section{Effect of Allium cepa on glycemic tolerance}

The glycemic tolerance effect of onion was assessed by the incremental areas under the glycemic response curves as depicted in Figure 1. Onion enhanced glycemic tolerance in DSO and DOE rats compared with the controls. However, the tolerance effect was more improved with the raw form. The glycemic response to glucose load in all experimental groups peaked at 60 minutes of the 2 hour-duration.

\section{Effect of Allium cepa on lipid profile}

Figure 2 expresses the effect of onion on the lipid profile of the grouped diabetic rats. After 6 weeks, onion caused significant $(P$ $<0.05$ ) decrease in TC, TG and LDL concentrations and significant increase in HDL concentration in DSO and DOE rats compared with the controls. In this study, onion extract impacts more antilipidemic effect than onion-supplemented diet. 


\section{Current Research in Diabetes \& Obesity Journal}

Table 3: Effect of Onion on venous mean FBS concentrations ( $n=5 /$ group).

\begin{tabular}{|c|c|c|c|}
\hline \multirow{2}{*}{ Parameters } & \multicolumn{3}{|c|}{ Experimental Diabetic Animal Groups } \\
\cline { 2 - 4 } & Control DC & Onion-Supplemented Diet-fed DSO & Onion Extract Treated DOE \\
\hline Final Mean FBS (mg/dL) & $192 \pm 15.5$ & $176.8 \pm 7.2$ & $167.8 \pm 19.1$ \\
\hline Initial Mean FBS (mg/dL) & $187.6 \pm 9.9$ & $196.6 \pm 6.9$ & $231.8 \pm 28.2$ \\
\hline$\%$ Change in Mean FBS & $2.35 \%$ & $-11.20 * \%$ & $-38.14 * * \%$ \\
\hline
\end{tabular}

Values are expressed in mean \pm SEM, ${ }^{* *}$ Significant $(\mathrm{P}<0.05)$ when compared with DC and DSO. *Significant when compared with $\mathrm{DC}$.

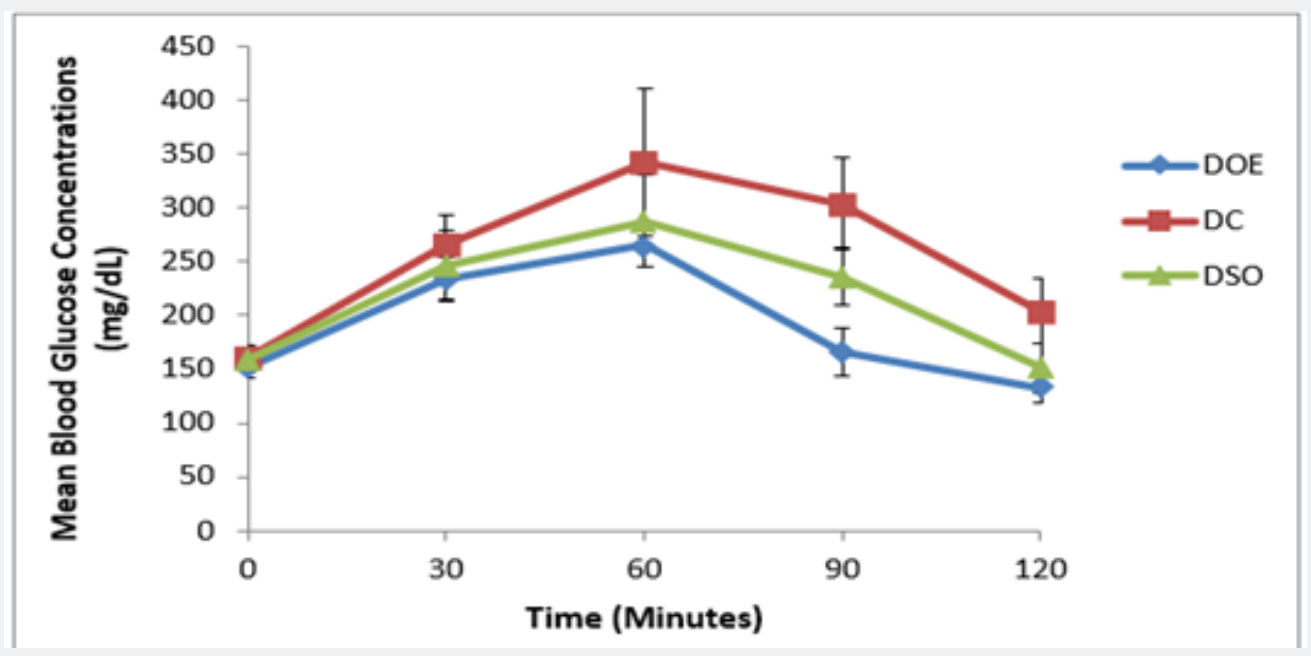

Figure 1: Effect of onion on glycemic tolerance profile ( $n=5 /$ group).

DC: Diabetic Control Rats; DSO: Onion Supplemented Diet-Fed Diabetic Rats; DOE: Onion Extract-Treated Diabetic Rats

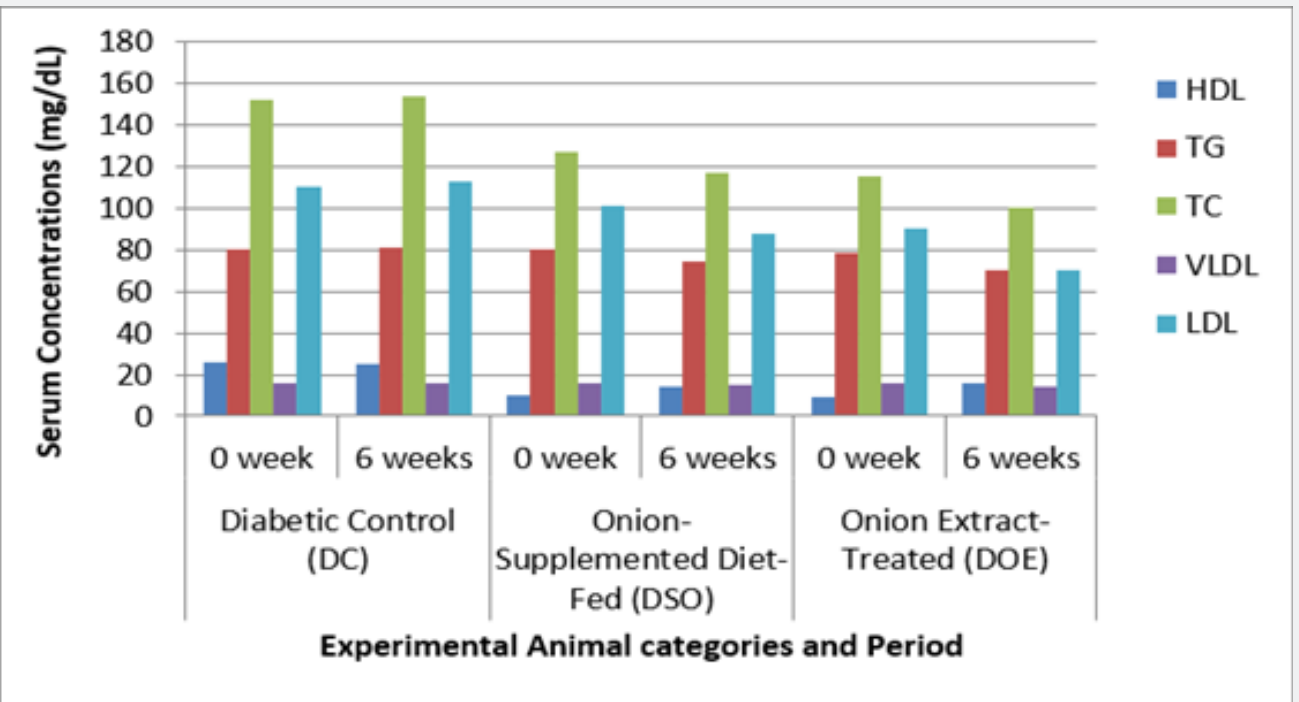

Figure 2: Effect of Onion on lipid profile in experimental diabetic rats $(n=5 / g r o u p)$.

DC: Diabetic Control Rats; DSO: Onion Supplemented Diet-Fed Diabetic Rats; DOE: Onion Extract-Treated Diabetic Rats; TC: Total Cholesterol; TG: Triglycerides; VLDL: Very Low-Density Lipoprotein; HDL: High Density Lipoprotein; LDL: Low Density Lipoprotein Cholesterol

\section{Discussion}

This nutritional study determined and compared the effects of mode of consumption of Allium cepa on body weight, glycemic tolerance/control and, lipid profile in diabetic rats with the rationale to provide basis for dietary selection, advice and recommendations for optimal beneficial effects. Findings obtained revealed that onion has antiobesity, hypoglycemic and 


\section{Current Research in Diabetes \& Obesity Journal}

antilipidemic properties which are more pronounced when consumed fresh than when ingested in mixed meal.

Consumption of onion in this study significantly reduced weight gain in diabetic rats. Onion was administered in two forms: as supplementation in mixed meal and as aqueous extract. The orally administered aqueous extract exhibits better weightlowering effect than the supplemented form as shown in Table 2. This observation interprets that consumption of onion as fresh bulb provides better results. However, many individuals are repugnant to taking onion in its raw form perhaps due to its nauseating smell or breath odour. As a result, most people preferred it in prepared mixed meal. Where an acute weight-lowering optimal effect is desired, consumption of onion in its raw form is advisable if no known allergy or adverse effects exhibited. To minimize the associated nausea, irritation or smell, raw onion can be taken sliced with vegetables, grains and salads. Few studies reported the toxicity of onions to certain animals such as dogs, cats, guinea pigs and many other animals. In this study, the stair case toxicity test was carried out to ensure that the maximum non-lethal dose $(4 \mathrm{~g} /$ kg body weight) was used to demonstrate the effects of onion in rats. This weight-lowering property of the onion may be attributed to its no fat or cholesterol, low calories content and rich source of quercetin, a type of antioxidant flavonoid that boosts metabolism and prevents fat accumulation [15]. Chartreuse onion contained the highest level of quercetin (163.3 mg/g DW) while it had low contents of other onions. Quercetin 3-glucoside and quercetin were documented in an average 93\%, 82.6\% and $77.8 \%$ of the quercetin glycosides in chartreuse, red and yellow onions respectively [16].

This study reveals that consumption of raw (extract) onion has more antihyperglycemic effect than when consumed in mixed meal as prepared in many traditional menus and cuisines in our environment. Allium сера is an herbaceous plant that has been shown to provide a hypoglycemic effect by regulating the activities of certain enzymes involved in carbohydrate metabolism, increasing insulin secretion and sensitivity, and enhancing NADP+ and NADPH activities, due to its content of organosulfur compounds and flavonoids such as quercetin [1]. This antidiabetic property of onion is also expressed in its impact on glycemic tolerance and profile as seen by the decrease in the incremental areas under the glycemic response curves of DOE and DSO rats compared with the control as shown in Figure 1. Onion significantly enhanced glycemic tolerance in DSO and DOE rats with more remarkable effect in DOE rats. The glycemic response to glucose load in the experimental groups was observed to peak at 60 minutes of the glucose challenge which suggests that the blood sugar lowering effect of onion can be manifest after one hour postprandial. Human and animal studies have shown that eating onions may help control blood sugar, which is especially significant for people with diabetes or prediabetes. A study [17] in human subjects with type 2 diabetes demonstrated that eating 3.5 ounces (100 grams) of fresh red onion reduced fasting blood sugar levels by about $40 \mathrm{mg} / \mathrm{dl}$ after four hours. Additionally, an animal study [18] also revealed that onion consumption may benefit blood sugar control.

Impact of onion on lipid profile is depicted in figure 2. In this study, onion caused significant decrease in TC, TG and LDL-C concentrations with significant increase in HDL concentration in DOE and DSO rats. However, raw onion extract impacts more beneficial antilipidemic effect than the onion-supplemented diet. This finding also suggests that the optimal effect is derived when onion is consumed in fresh or raw form than in mixed meal. Onions contain antioxidants and compounds that fight inflammation, decrease triglycerides and reduce cholesterol levels [18]. These potent anti-inflammatory properties may also help reduce high blood pressure and protect against blood clots. Quercetin a flavonoid antioxidant that's highly concentrated in onions, inhibits the enzyme $\alpha$-glucosidase, thus prevents the formation of D-glucose from oligosaccharides and disaccharides, and delays the absorption of glucose from the intestine [19]. Being a potent anti-inflammatory agent, it also helps in decreasing heart disease risk factors, such as high blood pressure [20]. The effect of onion on lipid profile in this study is similar to the findings of other studies using human and animal models which reported decrease in cholesterol and triglycerides concentrations with concomitant increase in HDL concentrations [20,21].

Nutrition habits have an important place in preventing and controlling DM which causes high health expenditures due to its acute and chronic complications. Although insulin therapy for Type $1 \mathrm{DM}$ has no alternative option, however, alternative treatment methods for Type $2 \mathrm{DM}$ disease have become important because oral antidiabetic drugs cause undesirable side effects. In this regard, several plant-derived products and naturally-derived products are currently used to provide support in treatment of diabetic patients. Consequently, screening of medicinal plants for therapeutic purposes is important in drug development as they may possess hypoglycemic, hypolipidemic and antioxidant activities which may be effective in the treatment of diabetes mellitus.

\section{Conclusion}

This study reveals that onion caused significant decrease in mean body weight gain with improved glycemic tolerance/control and lipid profile in experimental diabetic rats. It also revealed that consumption of onion in its raw form exerts quicker and better health benefits than when taken in mixed meals where the onion has been subjected to processing effects of boiling, frying, grilling, and so on. Therefore, based on the above findings, we conclude that the choice of mode of consumption of onion is significant when considering onion for therapeutic purposes.

\section{Statement of Authorship}

This work was carried out in collaboration between the authors. Author MMCA designed, supervised, performed the analysis and interpretation of data and wrote the manuscript 
while author POA assisted in the provision of essential materials and acquisition of data. Both authors read and approved the final manuscript for submission.

\section{References}

1. Akash MSH, Rehman K, Chen S (2014) Spice plant Allium cepa: Dietary supplement for treatment of type 2 diabetes mellitus. Nutrition 30 : 1128-1137.

2. Eldin IMT, Ahmed EM, Elwahab AHM (2010) Preliminary Study of the Clinical Hypoglycemic Effects of Allium cepa (Red Onion) in Type 1 and Type 2 Diabetic patients. Environ Health Insights 4: 71-77.

3. Ikechukwu OJ, Ifeanyi OS (2016) The Antidiabetic Effects of The Bioactive Flavonoid (Kaempferol-3-0- $\beta$-D-6 \{PCoumaroyl\} Glucopyranoside) Isolated from Allium cepa. Recent Pat Antiinfect Drug Discov 11: 44-52.

4. Block E, Birringer M, Jiang W, T Nakahodo, H J Thompson, et al. (2001) Allium chemistry: synthesis, natural occurrence, biological activity, and chemistry of Se-alk(en)ylselenocysteines and their $\gamma$-glutamyl derivatives and oxidation products. J Agric Food Chem 49: 458470.

5. Ly TN, Hazama C, Shimoyamada M, Ando H, Kato K, et al. (2005) Antioxidative compounds from the outer scales of onion. J Agric Food Chem 53: 8183-8189.

6. Urios P, Grigorova-Borsos AM, Sternberg M (2007) Flavonoids inhibit the formation of the cross-linking AGE pentosidine in collagen incubated with glucose, according to their structure. Eur J Nutr 46 139-146.

7. Kobori M, Masumoto S, Akimoto Y, Takahashi Y (2009) Dietary quercetin alleviates diabetic symptoms and reduces streptozotocininduced disturbance of hepatic gene expression in mice. Mol Nutr Food Res 53(7): 859-868.

8. Ramos FA, Takaishi Y, Shirotori M. (2006) Antibacterial and antioxidant activities of quercetin oxidation products from yellow onion (Allium сера) skin. J Agric Food Chem 54(10): 3551-3557.

9. Matheson EM, Mainous AG, Carnemolla MA (2009) The association between onion consumption and bone density in perimenopausal and postmenopausal non-Hispanic white women 50 years and older. Menopause 16(4): 756-759.
10.ASTM (1987) E 1163-87, Standard test method for estimating acute oral toxicity in rats. American Society for Testing Materials, Philadelphia PA, USA.

11. Weil CS (1972) Guidelines for experiments to predict the degree of safety of a material for man. Toxicol Appl Pharmacol 21: 194-199.

12. Teke GN, Kuete V (2014) Acute and Subacute Toxicities of African Medicinal Plants. Toxicological Survey of African Medicinal Plants.

13. National Research Council (US) Committee for the Update of the Guide for the Care and Use of Laboratory Animals (2011) Guide for the Care and Use of Laboratory Animals, ( $8^{\text {th }}$ edn.), National Academic Press, Washington DC, USA.

14. Friedewald WT, Levy RI, Fredrickson DS (1972) Estimation of the concentration of low-density lipoprotein cholesterol in plasma, without use of the preparative ultracentrifuge. Clin Chem 18: 499-502.

15. Gulsen A, Makris DP, Kefalas P (2007) Biomimetic oxidation of quercetin: isolation of a naturally occurring quercetin heterodimer and evaluation of its in vitro antioxidant properties. Food Res Int 40: 7-14.

16. Kwak JH, Seo JM, Kim NH, Arasu MV, Kim S, et al. (2017) Variation of quercetin glycoside derivatives in three onion (Allium cepa L.) varieties. Saudi J Biol Sci 24(6): 1387-1391

17. Taj EldinIM, Ahmed EE, Abd Elwahab HM (2010) Preliminary Study of the Clinical Hypoglycemic Effects of Allium cepa (Red Onion) in Type 1 and Type 2 Diabetic Patients. Environ Health Insights 4: 71-77.

18. Vessal M, Hemmati M, Vasei M (2003) Antidiabetic effects of quercetin in streptozotocin-induced diabetic rats. Comp Biochem Physiol C Toxicol Pharmacol 135(3): 357-364.

19. Kim HP, Mani I, Iversen L, Ziboh VA (1998) Effects of naturally occurring flavonoids and biflavonoids on epidermal cyclooxygenase and lipoxygenase from guinea-pigs. Prostaglandins Leukot. Essent Fatty Acids 58(1): 17-24.

20. Bang M, Kim HA, Cho YJ (2009) Alterations in the blood glucose, serum lipids and renal oxidative stress in diabetic rats by supplementation of onion (Allium cepa. Linn). Nutr Res Pract 3: 242-246.

21. Babu PS, Srinivasan K (1997) Influence of dietary capsaicin and onion on the metabolic abnormalities associated with streptozotocin induced diabetes mellitus. Mol Cell Biochem 175: 49-57.

\begin{tabular}{l} 
Your next submission with Juniper Publishers \\
will reach you the below assets \\
- Quality Editorial service \\
- Swift Peer Review \\
- Reprints availability \\
- E-prints Service \\
- Manuscript Podcast for convenient understanding \\
- Global attainment for your research \\
- Manuscript accessibility in different formats \\
( Pdf, E-pub, Full Text, Audio) \\
- Unceasing customer service \\
Track the below URL for one-step submission \\
https://juniperpublishers.com/online-submission.php \\
\hline
\end{tabular}

